\title{
The repellent role of institutions
}

Fernando Lannes Fernandes ${ }^{1}$

The quality of care needs to provide greater attention and humanization to users, not only with regard to building empathy, but also with regard to overcoming institutional barriers that can operate as decisive factors for adherence and full access to services. These barriers are not only the result of institutional or socio-legal mechanisms that regulate the functioning of institutions; they also place themselves, above all, at the core of the relationships and interactions between professionals and users of the system.

Here, we can address the issues of ethics and commitment, and even engagement, dedication and passion of professionals. Nevertheless, these dimensions alone, without a deeper analysis of their meanings and contexts, do not enable us to perform a more detailed reading of the true mechanisms that mobilize the dynamics of the access to health in terms of the moment where different elements are converged; which, in our case, refers to the relationship between professionals and users in the field of health care.

In the context of the field of health care, we have a convergence that brings together experiences that are often divergent, and that in other circumstances would not happen. This is the case, for example, of that health professional whose network of relationships, conviviality, cultural taste, world perspective and way of life are distant, for example, from the young black girl from the favela that accesses the system. From a Bourdieusian theoretical framework ${ }^{(1)}$, we can state that the set of predispositions defined by the habitus, and in a more externalized way, by the body hexis of each of these individuals, suggests a potential conflict, although this can be obliterated by the service protocols and the professional ethics, as well as by the genuine desire of that professional to 'welcome' the user.

Consequently, the moment that defines the convergence between the professional and the user needs to be investigated in terms of its complexity. For example, the way of dressing, communicating and addressing the user can be decisive in the emotive dimension of its adherence to the service. However, this relationship already implicitly carries with it a set of expectations that impose themselves and which can, in advance and alone, produce barriers unknown to the professionals - because they are already immersed in a sea of naturalizations that guide their views and actions in the world. Accordingly, the marks of social distinction highlighted by a shoe, a jewel, a haircut or a vanity case, or even the way of talking and behaving, can operate as subtle barriers that affect, for example, the self-esteem of the user.

Taken together, these factors associated with the broader context of the service space, configure what I have called, on other occasions, 'spaces of constraint' (or 'embarrassment'). In a more sophisticated way, I would call it the 'repellent' role of institutions, since these processes and dynamics do not necessarily produce 'constraints', but operate in such a way as to literally 'repel' users.

Starting from the concept of 'differentiation' that would be one of the dilemmas faced by frontline professionals (street level bureaucrats), from the logic of 'institutional efficiency' in achieving goals and best cost-benefit - 'business world tactics', the neoliberal public institutions became even more selective, thereby

${ }^{1}$ University of Dundee, Dundee, United Kingdom.

Corresponding author: Fernando Lannes Fernandes

University of Dundee, School of Education and Social Work, Pert Road, DD1 4HN, Dundee, United Kingdom. E-mail: f.l.fernandes@dundee. ac.uk 
privileging users who demand less resources and developing mechanisms that avoid, as far as possible, those that represent very complex cases and that require a lot of time and energy ${ }^{(2)}$.

Consequently, they reproduce this 'repellent' role because, like repellent substances, their main role is to create necessary barriers to prevent, in advance, that certain individuals have contact with the system. Here, a process similar to that investigated by Bourdieu in the educational system is also reproduced ${ }^{(3)}$.

The professional judgment is defined from a set of parameters and categories, which, in general, are based on the references of the world, ways of living and acting, defined by the habitus. Consequently, the same process that 'naturalizes' behaviors and ways of acting in the world will be the reference from which this judgment is established ${ }^{(4)}$.

The definition of new rules, new ways of thinking and doing, new mental and operational structures requires a permanent and systematic effort of reflexivity, disruption with the idea of naturalization and acceptance that things (and with them, practices) are immutable because they are what they are. This is not in the field of pure abstraction. It requires processes of change in the institutional culture and individual mentalities that can only be obtained from a regular, systematic and committed exercise. This seems to be a path that signalizes a new institutionality, besides new relationships among individuals in the context of these institutions and their places of convergence.

\section{References}

1. Bourdieu P. Razões práticas: sobre a teoria da ação. Campinas: Papirus; 2011.

2. Lipsky M. Street-level bureaucracy: dilemmas of the individual in public services. New York: Russell Sage Foundation; 1980.

3. Bourdieu P, Saint-Martin M. As categorias do juízo professoral. In: Nogueira MA, Caiani A, organizadores. Escritos de educação. Petrópolis: Vozes; 1998. p.185-216.

4. Fernandes FL, Swinney A, McMillan S, MacLeay D, McGhee J, Graham W, et al. Rehabilitation doxa and practitioner judgment. Symbolic drivers for health care in the Scottish prison system. Ciênc Saúde Coletiva. 23(9):2869-77. doi: http://dx.doi.org/10.1590/1413-81232018239.13412018 